\title{
Sperm DNA analysis in a Friedreich ataxia premutation carrier suggests both meiotic and mitotic expansion in the FRD $A$ gene
}

\author{
M B Delatycki, D Paris, R J M Gardner, K Forshaw, G A Nicholson, N Nassif, \\ $R$ Williamson, $S$ M Forrest
}

\begin{abstract}
Friedreich ataxia is usually caused by an expansion of a GAA trinucleotide repeat in intron 1 of the FRDA gene. Occasionally, a fully expanded allele has been found to arise from a premutation of 100 or less triplet repeats. We have examined the sperm DNA of a premutation carrier. This man's leucocyte DNA showed one normal allele and one allele of approximately 100 repeats. His sperm showed an expanded allele in a tight range centering on a size of approximately 320 trinucleotide repeats. His affected son has repeat sizes of 1040 and 540. These data suggest that expansion occurs in two stages, the first during meiosis followed by a second mitotic expansion. We also show that in all informative carrier father to affected child transmissions, with the notable exception of the premutation carrier, the expansion size decreases.

(F Med Genet 1998;35:713-716)
\end{abstract}

Keywords: Friedreich ataxia; trinucleotide repeats; premutation; sperm

Friedreich ataxia (FRDA) is an autosomal recessive neurodegenerative disorder with an incidence in the European population of approximately 1 in $50000^{1}$ and a carrier prevalence of approximately 1 in $100 .^{1-3}$ The disease usually presents with progressive gait and limb ataxia, absent tendon reflexes, and pyramidal weakness in the legs, as well as loss of position and vibration sense, and cardiomyopathy is commonly present. ${ }^{3}$ After initial studies linked the gene to the region 9q13-q21.1, Campuzano et al’ showed that FRDA is the result of mutations in the FRDA gene (previously known as $X 25$ ) which encodes a protein called frataxin. This protein contains 210 amino acids and appears to be a mitochondrial protein. $^{6-9}$ The putative yeast homologue of frataxin, $Y f h 1 p$, has recently been shown to be involved in the regulation of mitochondrial iron homeostasis and respiratory function. ${ }^{8} 10$

More than $95 \%$ of affected alleles have an expansion in the number of GAA triplet repeats in intron 1 of $F R D A .^{5}{ }^{11} 12$ Normal alleles contain between six and 36 GAA repeats, ${ }^{13}$ and disease causing expanded alleles have been observed in a range from $66-1700$ repeats, ${ }^{212}$ with the great majority between 700 and 1200 repeats. Expansions between 40 and 100 repeats have been described as premutation alleles, and can either expand further in one generation into full mutations or can be transmitted as a premutation. ${ }^{213} 14$

An increase in the number of triplet repeats correlates with the clinical severity with the size of the smaller allele being more significant in this regard. ${ }^{11} 1215$ Where an affected person has only one allele with an expansion, point mutations have been found in the other copy of the FRD $A$ gene..$^{5116}$ No FRDA patients have yet been found who are homozygous for a point mutation.

Until the finding that an expanded GAA trinucleotide repeat causes FRDA, all other conditions with triplet repeat expansions were autosomal dominant or $\mathrm{X}$ linked. ${ }^{17}$ Instability of trinucleotide repeat size occurs in all of these disorders. In some, maternal transmission is more likely to lead to the child receiving a significantly larger expansion (myotonic dystrophy (DM), fragile X-A syndrome (FRAXA)). In the autosomal dominant conditions with $\mathrm{CAG}_{\mathrm{n}}$ expansions, paternal transmission shows preferential expansion (Huntington's disease (HD), DRPLA, SCA1, SCA7, MJD). ${ }^{18} 19$

We have studied the $F R D A$ mutations in 66 Australian patients with FRDA from 45 families and their parents where available. We have identified a male premutation carrier, where sperm studies have provided information about the timing of the expansion process in FRDA. We have also examined the alteration in allele size upon transmission from carrier parents to affected children.

\section{Methods}

PATIENTS AND FAMILIES

Patients were ascertained either through response to a request in a support group newsletter or by referral from their neurologist. Thirty-eight of the 42 patients on whom clinical details were available were examined by one of the authors (MBD, RJMG, GAN). Clinical information on the others was obtained from their neurologist or clinical geneticist. Where available, parental blood samples were collected. The patients were defined as either typical or atypical based on the diagnostic criteria of Harding. ${ }^{3}$ Categorisation for scoring of parental allele transmission is described in table 1.

GENOMIC DNA EXTRACTIONS

Whole blood was collected from patients in both lithium heparin and EDTA tubes. Blood leucocytes were extracted using a Progenome 


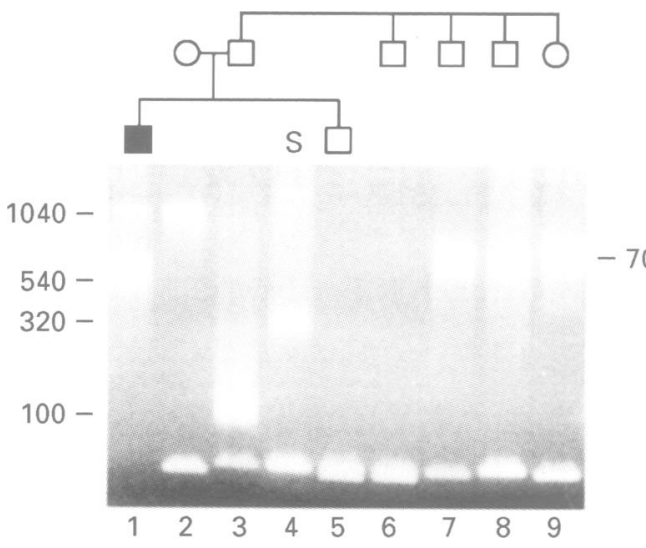

Figure 1 Analysis of $G A A$ repeat expansions showing that the son (lane 1) affected with FRDA has alleles with $G A A$ repeat lengths of 1040 and 540, his mother (lane 2) with a normal allele and one of 1040, and his father with a premutation of 100 repeats (lane 3) in addition to a normal allele. His father's sperm has a compact band of $320 \mathrm{GAA}$ repeats (lane 4) in addition to a normal allele. The other son of the premutation carrier has two normal alleles (lane 5) as does a brother (lane 6), while three other sibs are carriers of full mutation alleles of 700 repeats lanes 7-9). " $S$ " refers to sperm DNA from the premutation carrier father.

II DNA Extraction Kit (Progen Ltd). Sperm DNA was extracted from semen using the protocol of Jeffreys et al. ${ }^{20}$

\section{PCR AMPLIFICATION}

Patients had their DNA analysed using the oligonucleotides GAA-F and GAA-R from Campuzano et aP with the GeneAmp XL Long PCR Reagent Kit (Perkin-Elmer). These primers gave a product of $457+3 n$ bp (where $\mathrm{n}=$ number of GAA repeats). Reactions contained 25-150 ng genomic DNA, $0.2 \mathrm{mmol} / 1$ each $\mathrm{dNTP}, 1 \mu \mathrm{mol} / 1$ each primer, $1.5 \mathrm{mmol} / 1$ $\mathrm{Mg}^{2+}$ (EDTA samples) or $3.0 \mathrm{mmol} / 1 \mathrm{Mg}^{2+}$ (Lithium Heparinised samples), and 2.0 units rTth (Thermus thermophilus) DNA polymerase $\mathrm{XL}$. Other conditions were as recommended by the manufacturer. The cycling reaction involved $95^{\circ} \mathrm{C}$ for five minutes, followed by 10 cycles of $95^{\circ} \mathrm{C}$ for one minute and $68^{\circ} \mathrm{C}$ for three minutes, then 10 cycles at $95^{\circ} \mathrm{C}$ for one minute and $68^{\circ} \mathrm{C}$ for seven minutes, finishing with 10 cycles of $95^{\circ} \mathrm{C}$ for one minute and $68^{\circ} \mathrm{C}$ for 10 minutes. The whole PCR product was then analysed on a $0.8 \%$ agarose low electroendosmosis gel (LE, BoehringerMannheim) and the size of the expansion relative to the molecular weight standard marker $\mathrm{C}$ (Boehringer-Mannheim) was determined using EAGLE EYE 3.0 software (Stratagene). Errors in estimation of triplet repeat expansion numbers was \pm 20 for expanded alleles and \pm 3 for alleles in the normal range.
GENOMIC SOUTHERN BLOTTING.

Genomic Southern blotting was done to confirm some of the PCR banding patterns, using digestion with the enzyme BsiHKAI (New England Biolabs). This yielded a DNA fragment of normal allele size of $2.4 \mathrm{~kb}$. Five $\mu \mathrm{g}$ DNA was digested at $60^{\circ} \mathrm{C}$ with $B s i \mathrm{HKAI}$ and the total amount run on a $0.8 \%$ agarose LE gel in parallel with the molecular weight standard marker C (Boehringer-Mannheim). The DNA was then blotted on Hybond $\mathrm{N}+$ membranes (Amersham) and probed with a labelled $240 \mathrm{bp}$ fragment containing exon 1 of the FRDA gene.

\section{Results}

SPERM DNA ANALYSIS IN A PREMUTATION CARRIER

Of 56 parents tested, only one had a premutation. His son has classical FRDA (onset at 10 years, areflexia, reduced vibration sense and proprioception, cardiomyopathy) with alleles of approximately 1040 and 540 repeats. The father has one allele in the normal range and one expanded allele of about 100 repeats. In order to ascertain the timing of trinucleotide repeat expansion between father and son, the GAA expansion in sperm DNA from the father was assessed. This showed a compact band of approximately 320 GAA repeats with a second allele in the normal range (fig 1). This is the only definite example out of 34 father to offspring transmissions that we have examined where there is an increase in the GAA repeat size. Results consistent with paternity were found using CA repeats on chromosomes 5 and 11 (data not shown).

The parents of the premutation carrier are dead but other relatives were available for study. Three of his sibs have now been shown to be carriers, all of them having the same sized fully expanded allele of 700 GAA repeats. Another sib has not received an expanded allele. An unaffected son of the premutation carrier has also not received an expanded allele (fig 1).

\section{GAA REPEAT ANALYSIS}

A total of 64 out of 66 patients had only expanded GAA repeat alleles in intron 1 of the FRDA gene while two brothers were compound heterozygotes, having one expanded allele and a point mutation (paternally inherited $\mathrm{G} 130 \mathrm{~V}$ ) in the second allele. The range of expanded allele size in patients was from 3301390 repeats. The mean expanded allele size was 869 (SD 217) and the mean large and small allele sizes individually were 964 (SD 205) and 770 (SD 184) respectively.

Table 1 Categorisation for scoring allele transmission from parent to affected child

\begin{tabular}{ll}
\hline Category & Explanation* \\
\hline Definitely expanded & Both alleles of child larger than parent's expanded allele \\
Definitely contracted & Both alleles of child smaller than parent's expanded allele \\
No change & Both alleles of child and the expanded parental allele were of the same size \\
No change or possible contraction & Parental allele was the same size as one of the child's alleles but larger than the other \\
No change or possible expansion & Parental allele was the same size as one of the child's alleles but smaller than the other \\
Contraction or expansion & Parental allele was intermediate in size between the two alleles in the child
\end{tabular}


Table 2 Trends in allele size transmission from parent to child

\begin{tabular}{lllllll}
\hline & $\begin{array}{l}\text { Definitely } \\
\text { decreased }\end{array}$ & $\begin{array}{l}\text { Definitely } \\
\text { increased }\end{array}$ & $\begin{array}{l}\text { Increased or } \\
\text { decreased }\end{array}$ & $\begin{array}{l}\text { Decreased or no } \\
\text { change }\end{array}$ & $\begin{array}{l}\text { No } \\
\text { change }\end{array}$ & Total \\
\hline Father & 17 & 1 & 12 & 3 & 1 & 34 \\
Mother & 19 & 9 & 13 & 5 & 1 & 47 \\
Total & 36 & 10 & 25 & 8 & 2 & 81 \\
\hline
\end{tabular}

\section{PARENTAL TRANSMISSION}

There were 56 parents (24 paternal, 32 maternal) on whom DNA studies were undertaken. They had an expanded range of 100 to 1420 GAA repeats; 81 parent to affected child transmissions were available for analysis. The data set was not fully informative as the parental origin of each expanded allele in the child could not be unambiguously determined in some cases. The mean parental expansion size was 982 (SD 215) with that for maternal expansion size being 998 (SD 186) and for paternal alleles 961 (SD 252). When compared to the mean allele size in their offspring, there is an indication that the alleles have the potential to decrease in size.

In $17 / 34$ paternal transmissions, a decrease in allele size was confirmed unequivocally (table 2), and in a further four cases there was either a decrease or no change in size. In 12/34 of cases it was not possible to say if the allele had expanded or contracted in size. The transmission from the premutation carrier father to his affected son is the only definite case of an increase in allele size.

The results of maternal transmissions were that 19/47 GAA expansions definitely decreased in length, and a further six either decreased or remained the same; $9 / 47$ definitely increased in length (table 2). In 13/47 of cases, it was not possible to be certain whether the allele had increased or decreased in size.

\section{Discussion}

We have shown that the expansion profile from sperm DNA of an FRDA premutation carrier is different from that seen in sperm DNA of full mutation carriers. In three full mutation carrier males, sperm DNA GAA repeat length was always shorter than that seen in their leucocyte DNA. ${ }^{21}$ In that report, the expanded sperm DNA band was present as a smear indicating that when reduction of GAA repeat number occurred during meiosis, this was very variable in its extent, resulting in sperm having a wide range of trinucleotide repeat numbers.

In contrast, in our study, the sperm DNA of the carrier father with the premutation allele has an expanded allele larger than that seen in his leucocyte DNA and it is present in a relatively tight band. This may indicate that meiotic GAA expansion from a premutation is fairly constant in the size of the expansion generated to the resultant spermatozoa. However, this is still smaller than either of the alleles in his affected son. We propose that a two step instability process exists, one prezygotic during generation of sperm, and a second step occurring postzygotically. We cannot exclude the possibility that some sperm are present with a higher repeat number, which results in the son having an allele with a higher repeat number than is seen in the visible band in his father's sperm DNA study. The occurrence of somatic mosaicism between leucocytes and testes resulting in sperm precursors having a larger expansion than that seen in leucocyte DNA is another possible explanation for these findings.

We found no definite example of an increase in size of GAA repeat size in a father to affected child transmission apart from the premutation case described. In FRDA, data have been published for parent to carrier child transmissions of the GAA repeat and here $8 / 13$ contractions of the maternal allele and 9/9 contractions of the paternal allele was observed. ${ }^{21} \mathrm{~A}$ recent report indicates that in FRDA, carrier fathers with an allele towards the smaller end of the full mutation expansion range may transmit an allele which increases in size to their offspring, while the children of those males with larger alleles receive a GAA repeat which is smaller than that of their father. ${ }^{22}$ This report makes assumptions about parental allele assignment to affected offspring; in our study, if the parental allele was between the sizes of the alleles of the affected child, the transmission was not included in our analysis and we made no assumptions about which allele came from which parent.

Transmission data and sperm DNA analyses for other trinucleotide repeat disorders are of interest in interpreting our data. In FRAXA and $\mathrm{DM}$ the size of the trinucleotide repeat expansions are similar to that seen in FRDA. Unlike other trinucleotide repeat disorders, in these three diseases the expansion is not within an exon. In males with full mutation FRAXA, the repeat number in sperm reverts from the fully expanded to the premutation range. ${ }^{23}$ Premutation carrier males never pass a fully expanded mutation to their offspring. ${ }^{24}$ Males with DM alleles greater than 700 repeats have similar or smaller repeats in sperm; those with small or intermediate sized alleles have a wide range of allele sizes, both smaller and larger than that seen in leucocyte DNA. ${ }^{25}$ Expansions of greater than 1000 repeats were not seen. We show that there is consistent decrease in expansion size in FRDA from father to affected child. It may be that large expansions of the order of hundreds to thousands of trinucleotide repeats, as is seen in FRDA, DM, and FRAXA, are not stable in sperm and are therefore selected against, leading to reduction in repeat number during transmission of alleles from the father.

Timing of trinucleotide repeat instability is not certain in any trinucleotide repeat disorders. In FRAXA it was thought to occur postzygotically with sparing of the male germline, ${ }^{23}$ but recent evidence suggests that transition from premutation to full mutation in FRAXA is likely to be prezygotic. ${ }^{26}$ It is suggested that the finding of only premutation alleles in the sperm of full mutation FRAXA males is because of selection against full mutations in the male germline.$^{26}$ The occurrence of postzygotic instability is supported by the finding of mosaicism for expansion size in different tissues in $\mathrm{DM}^{27}$ and FRDA. ${ }^{15}$ Our findings 
support a combination of pre- and postzygotic expansion events.

The discovery that expansion of the trinucleotide GAA in the first intron of FRDA is the major cause of autosomal recessive Friedreich ataxia poses further challenges for understanding the biology of unstable trinucleotide repeats. Many models have been proposed to explain how the trinucleotide repeats can expand or contract. Studies on rare or unusual cases, such as the sperm analysis of the premutation carrier presented here, can indicate more general mechanisms relating to this unusual non-mendelian process.

The first two authors contributed equally to this work. The authors would like to thank the Friedreich's Ataxia Association of Victoria, the Friedreich's Ataxia Association of Queensland, the Apex Club of Elmore, and donors from New South Wales. The Murdoch Institute receives a Block Grant from the NH\&MRC, and MBD is an NH\&MRC Research Scholar. We bish the thank family in Holland and sending them to us.

1 Filla A, De Michele G, Marconi R, et al. Prevalence of hereditary ataxias and spastic paraplegias in Molise, region of Italy. $\mathcal{F}$ Neurol 1992;239:351-3.

2 Epplen C, Epplen J, Frank G, Miterski B, Santos E, Schols L. Differential stability of the (GAA)n tract in the Friedreich ataxia (STM7) gene. Hum Genet 1997;99:834-6.

3 Harding AE. Friedreich's ataxia: a clinical and genetic study of 90 families with an analysis of early diagnostic criteria and intrafamilial clustering of clinical features. Brain 1981; and intrafamilia

4 Chamberlain S, Shaw J, Rowland A, et al. Mapping of mutation causing Friedreich's ataxia to human chromosome 9. Nature 1988;334:248-50.

5 Campuzano V, Montermini L, Molto MD, et al. Friedreich's ataxia: autosomal recessive disease caused by an intronic GAA triplet repeat expansion. Science 1996;271:1423-7.

6 Koutnikova H, Campuzano V, Foury F, Dolle P, Cazzalin $O$, Koenig $M$. Studies of human, mouse and yeast homologues indicate a mitochondrial function for frataxin Nat Genet 1997;16:345-51.

7 Priller J, Scherzer CR, Faber PW, MacDonald ME, Young $A B$. Frataxin gene of Friedreich's ataxia is targeted to mitochondria. Ann Neurol 1997;42:265-9.

8 Babcock M, de Silva D, Oaks R, et al. Regulation of mitochondrial iron accumulation by Yfhlp, a putative mitochondrial iron accumulation by Yfhlp,

9 Wilson R, Roof D. Respiratory deficiency due to loss of mitochondrial DNA in yeast lacking the frataxin homomitochondrial DNA in yeast lackin
logue. Nat Genet 1997;16:352-7.
10 Foury F, Cazzalini O. Deletion of the yeast homologue of the human gene associated with Friedreich's ataxia elicits iron in mitochondria. FEBS Lett 1997;411:373-7.

11 Filla A, De Michele G, Cavalcanti F, et al. The relationship between trinucleotide (GAA) repeat length and clinical features in Friedreich ataxia. Am $\mathcal{F}$ Hum Genet 1996;59: 554-60.

12 Durr A, Cossee M, Agid Y, et al. Clinical and genetic abnormalities in patients with Friedreich's ataxia. $N$ Engl $\mathcal{F}$ Med 1996;335:1169-75.

13 Montermini L, Andermann E, Labuda M, et al. The Friedreich ataxia GAA triplet repeat: premutation and normal alleles. Hum Mol Genet 1997;6:1261-6.

14 Cossee M, Schmitt M, Campuzano V, et al. Evolution of the Friedreich's ataxia trinucleotide repeat expansion: founder
effect and premutation. Proc Natl Acad Sci USA 1997;94: 7452-7.

15 Montermini L, Richter A, Morgan $\mathrm{K}$, et al. Phenotypic variability in Friedreich ataxia: role of the associated GAA triplet repeat expansion. Ann Neurol 1997;41:675-82.

16 Bidichandani SI, Ashizawa T, Patel PI. Atypical Friedreich ataxia caused by compound heterozygosity for a novel missense mutation and the GAA triplet-repeat expansion. $A m$ ₹ Hum Genet 1997;60:1251-6.

17 Rosenberg RN. DNA-triplet repeats and neurologic disease. $N$ Engl f Med 1996;335:1222-4.

18 David G, Abbas N, Stevanin G, et al. Cloning of the SCA7 gene reveals a highly unstable CAG repeat expansion. Nat Gene reveals a highly $1997 ; 17: 65-70$.

19 Gusella JF, MacDonald ME. Trinucleotide instability: a repeating theme in human inherited disorders. Annu Rev repeating theme in hum
Med $1996 ; 47: 201-9$.

20 Jeffreys AJ, Tamaki K, MacLeod A, Monckton DG, Neil DL, Armour JA. Complex gene conversion events in germline mutation at human minisatellites. Nat Genet 1994;6: 136-45.

21 Pianese L, Cavalcanti F, De Michele G, et al. The effect of parental gender on the GAA dynamic mutation in the FRDA gene. Am $\mathcal{f}$ Hum Genet 1997;60:460-3.

22 Monros E, Molto MD, Martinez F, et al. Phenotype correlation and intergenerational dynamics of the Friedreich ataxia GAA trinucleotide repeat. Am $\mathcal{f}$ Hum Genet 1997;61:101-10.

23 Reyniers E, Vits L, De Boulle K, et al. The full mutation in the FMR-1 gene of male fragile X patients is absent in their the FMR-1 gene of male fragile $X$

24 Yu S, Mulley J, Loesch D, et al. Fragile-X syndrome: unique genetics of the heritable unstable element. Am $\mathcal{f}$ Hum Genet 1992;50:968-80.

25 Jansen G, Willems $P$, Coerwinkel $M$, et al. Gonosomal mosaicism in myotonic dystrophy patients: involvement of mitotic events in (CTG)n repeat variation and selection against extreme expansion in sperm. Am 7 Hum Genet 1994;54:575-85.

26 Mouton C, Vincent MC, Biancalana V, Mandel JL. Transition from premutation to full mutation in fragile $\mathrm{X}$ syndrome is likely to be prezygotic. Hum Mol Genet 1997;6: 971-9.

27 Massari A, Gennarelli M, Menegazzo E, et al. Postzygotic instability of the myotonic dystrophy $\mathrm{p}$ [AGC] in repeat amplifications in sperm. $\mathcal{F}$ Neurol 1995;242:379-83. 